\title{
Investigating the Role of an Inquiry-Based Biology Lab Course on Student Attitudes and Views toward Science
}

Erica Jeffery, ${ }^{\dagger}$ Kathy Nomme, ${ }^{* *}$ Thomas Deane, ${ }^{\dagger}$ Carol Pollock, ${ }^{\ddagger}$ and Gülnur Birol $\$$

'Biology Program, Departments of Botany and Zoology, "Department of Zoology, and \$Science Centre for Learning and Teaching, Faculty of Science, University of British Columbia, Vancouver, BC V6T 1Z4, Canada

\begin{abstract}
Students' academic experiences can influence their conceptualization of science. In contrast experts hold particular beliefs, perceptions, opinions, and attitudes about science that are often absent in first-year undergraduate students. Shifts toward more expert-like attitudes and views have been linked to improved student engagement, critical-thinking ability, conceptual understanding, and academic performance. In this study, we investigate shifts in attitudes and views toward science by students in four biology classes with differences in student enrollment, academic support, and instruction. We observe significant, positive effects of enrollment in a guided-inquiry lab course and academic performance on the percentage of expert-like student attitudes and views at the end of term. We also identify variation in two aspects of student attitudes and views: 1) confidence and interest and 2) understanding and acceptance. In particular, enrollment in the lab course boosts student confidence and interest in scientific inquiry in the short term, even for students with low academic performance or little English-language experience. Our results suggest that low-performing students in particular may require additional opportunities for experiential learning or greater academic support to develop expert-like perceptions of biology as a science.
\end{abstract}

\section{INTRODUCTION}

Students begin their undergraduate studies with ideas about what science is and how it is studied that may be very different from those of experts (Edmondson and Novak, 1993; Gire et al., 2009; Desaulniers Miller et al., 2010; Semsar et al., 2011; Hansen and Birol, 2014). Although there is some debate about the nature of science (for discussion, see Lederman et al., 2002; Liang et al., 2008), there is general agreement that experts view scientific knowledge as tentative, changeable, and influenced by culture and experience. Experts also recognize that creativity is required when creating hypotheses, designing experiments, and analyzing data (Abd-El-Khalick and Lederman, 2000; Liang et al., 2008). In contrast, students often view science as a defined body of knowledge and experimental inquiry as following a predetermined, rigid protocol. This sort of non-expert-like thinking by students is common in many disciplines, including biology (Allen and Tanner, 2009). One of the goals of science education is to shift students toward a more expert-like conceptualization of the nature of science, assisting students in overcoming cultural and societal biases if necessary (National Research Council [NRC], 1996; Hiebert, 2007; American Association for the Advancement of Science [AAAS], 2011; Hoskins et al., 2011).

Undergraduate courses with associated laboratory components provide an opportunity for students to actively engage in the process of scientific inquiry. Through laboratory activities, students can practice the critical-thinking and problem-solving skills that are required to design, implement, and interpret the results of an experiment and
Jennifer Knight, Monitoring Editor Submitted November 9, 2014; Revised June 6, 2016; Accepted June 7, 2016

CBE Life Sci Educ December 1, 2016 15:ar61 DOI:10.1187/cbe.14-11-0203

*Address correspondence to: Kathy Nomme (nomme(azoology.ubc.ca)

() 2016 E. Jeffery et al. CBE-Life Sciences Education @ 2016 The American Society for Cell Biology. This article is distributed by The American Society for Cell Biology under license from the author(s). It is available to the public under an Attribution-Noncommercial-Share Alike 3.0 Unported Creative Commons License (http:// creativecommons.org/licenses/by-nc-sa/3.0) "ASCBß" and "The American Society for Cell Biology ${ }^{\circledR}$ " are registered trademarks of The American Society for Cell Biology. 
develop practical skills such as the use of equipment or specific techniques. By participating in scientific inquiry, students experience what it is like to contribute to scientific knowledge and are exposed to the tentative nature of science. Instructors can explicitly address elements of the nature of science as they guide students toward thinking and acting more like expert scientists. Education research has shown participation in inquiry to be an effective way of increasing student understanding, efficacy, enjoyment, and interest in science (AAAS, 2011; Hanauer and Dolan, 2014). However, without explicit instruction and experience in scientific inquiry, students may retain non-expertlike interpretations of how scientific knowledge is obtained (Eastwell, 2010). Furthermore, they may continue to view the process of science as inaccessible and/or personally irrelevant (Prince, 2004; Ambrose et al., 2010).

Students' attitudes and perceptions about science can influence their level of engagement and, ultimately, their conceptual learning and academic performance (Osborne et al., 2003; Hofer, 2004; Deslauriers et al., 2011). Students who appreciate how science impacts their lives are more motivated to engage in scientific thinking (Allen and Tanner, 2005; Smith et al., 2005). They may also be better able to generate research questions and to design valid experiments that address those questions (Campisi and Finn, 2011). Students who have greater confidence and familiarity with scientific inquiry may also be more rigorous in critiquing experimental designs and evaluating the validity of evidence. There is therefore increasing interest in investigating and documenting both shifts in student attitudes and associated learning (Osborne et al., 2003; Perkins et al., 2005; Partin et al., 2011; Partin and Haney, 2012; Beck et al., 2014), and many tools have been developed for assessing student attitudes and views toward various aspects of science (Lederman et al., 1998, 2002; Tsai and Liu, 2005; Adams et al., 2006; Liang et al., 2006; Chen et al., 2013).

In assessing shifts in student attitudes, researchers need to be cognizant of how the transition to undergraduate studies and their students' cognitive development can impact students' learning (Perry, 1981; Bandura, 1986; Briggs et al. 2012). Most first-year undergraduate biology students have been academically successful in high school and often arrive at university confident in their beliefs about biology as a science and their own ability to succeed. If those beliefs are challenged during their first year of university, students may initially experience confusion and undermining of their sense of self-efficacy, which can lead to lower motivation to apply themselves (Ambrose et al., 2010). After their first year as undergraduates, students may demonstrate a decrease in confidence and revert to nonexpert-like attitudes regarding science (Adams et al., 2006; Barbera et al., 2008; Butler et al., 2008; Semsar et al., 2011; Ding and Mollohan, 2015). For high-performing biology students, an initial decrease in expert-like attitudes may be followed by recovery and a move to more expert-like attitudes by the time students are in their fourth year of studies (Hansen and Birol, 2014). Low-performing students, however, may continue to demonstrate poor affective, behavioral, and cognitive outcomes in the biological sciences without targeted instruction or academic support. Identification of the factors that influence students' attitudes in first-year biology and beyond would help to inform science educators as they strive to guide students toward a more expert-like understanding of science.
In this study, we investigate the attitudes and views of firstyear students regarding the nature of biology as a science and scientific inquiry in biology. We also ask whether-and howthese traits change over the course of one term, and whether enrollment in an inquiry-based lab is associated with student transitions toward more expert-like attitudes and views.

\section{METHODS \\ Study Populations}

This study investigated the attitudes and views of 452 students enrolled in first-year biology classes at a large Canadian research university (student body: $\sim 52,000$ students total, $\sim 41,000$ undergraduates). Total enrollment in the first-year biology program is more than 1800 students per year. These first-year students arrive with variable prior experiences in high school science and choose to enroll in one of three different options for the same first-year biology course. These three lecture-based course options focus on similar topics in first-year biology (genetics, evolution, and ecology), but they differ in terms of enrollment criteria, class size, and pedagogy (Table 1). Classes A (surveyed in term 1) and B (surveyed in term 2) are both standard program classes with relatively large enrollment (up to 225 students per section). These sections are open to both science majors and nonmajors, but the majority of students are declared science majors with average high school grades of $\geq$ $90 \%$. Students in these classes have access to drop-in help at the course Learning Centre. In contrast, class C (surveyed in term 2) is restricted to first-year students who are enrolled in a coordinated first-year science program (enrollment in this program is limited to 170 students per year). Students self-select for this cohort-based program and are automatically enrolled in the same sections of first-year biology, chemistry, and physics lecture and lab courses and in a calculus course. In addition to the lecture portion of the course, students in this program also attend required tutorials once a week (Table 1). Class D (surveyed in term 1 ) is part of a cohort-based program restricted to 75 first-year science students who are selected via a competitive application process. These students receive integrated instruction in the four science disciplines (including both lectures and workshops) and are enrolled in the same sections of first-year biology, chemistry, and physics labs.

A number of students we surveyed were also enrolled in the first-year biology laboratory course offered at this institution. This course guides students through the process of scientific inquiry: developing hypotheses, designing and conducting an experiment, analyzing data, presenting an oral report, and submitting a journal-style article describing their work. For students in classes A and B, enrollment in this lab course is optional (students in either class may or may not be enrolled in one of the multiple sections of lab courses offered each term; see Table 2). For students in classes $C$ and $D$, enrollment in the firstyear lab course is mandatory; students in class $\mathrm{C}$ are enrolled in term 2 , and students in class $\mathrm{D}$ are enrolled in term 1.

\section{Survey Development}

Several quantitative survey tools have been developed to assess student attitudes and views regarding the nature of science (Lederman et al., 2002; Tsai and Liu, 2005; Adams et al., 2006; Liang et al., 2006; Chen et al., 2013; for a list of earlier instruments, see Lederman et al., 1998). We were specifically 
TABLE 1. Description of the three different first-year biology lecture courses sampled in this study and comparison with the first-year lab course

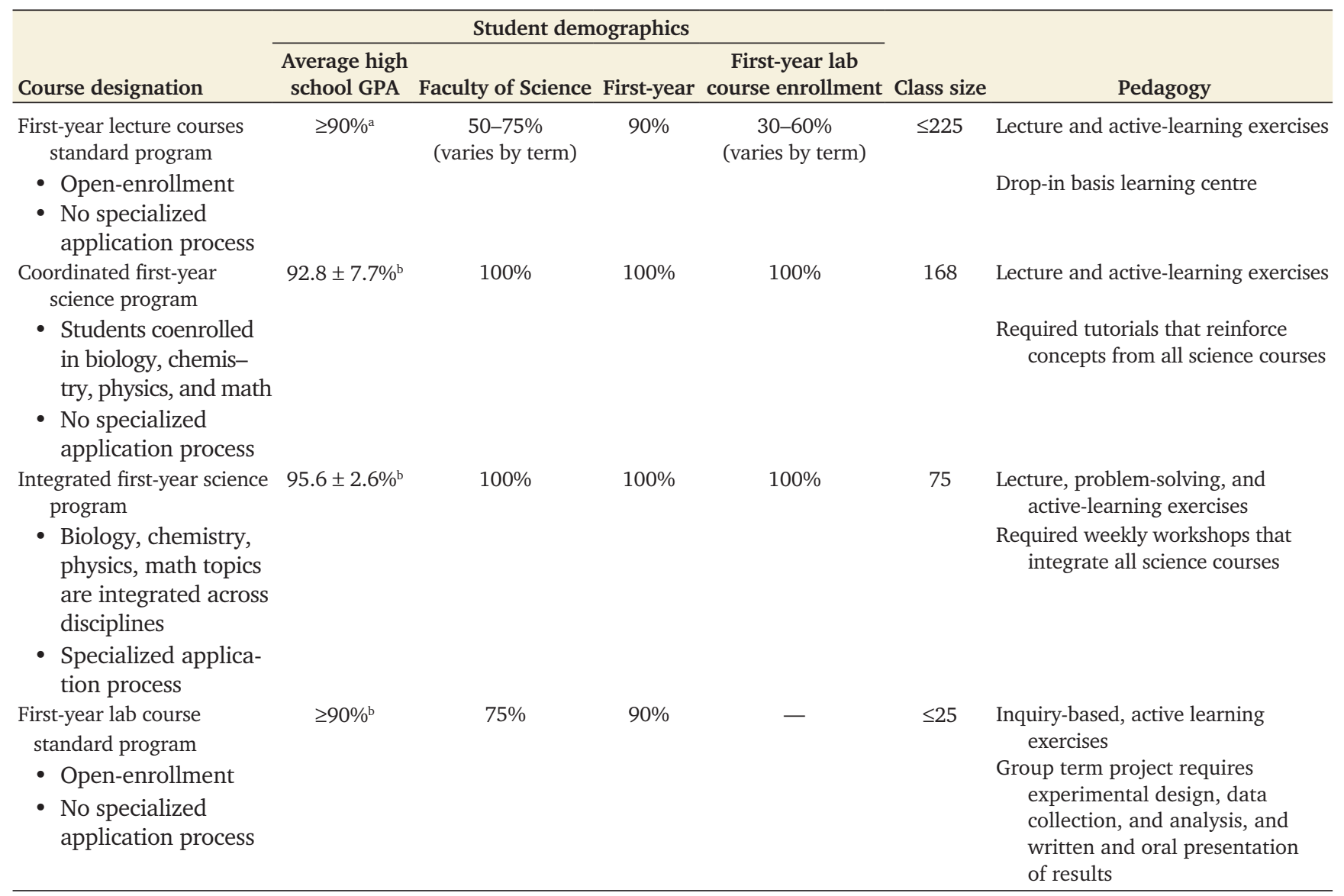

average high school GPA of first-year Faculty of Science students at this institution.

${ }^{\mathrm{b}}$ Mean high school GPA \pm SD of all students enrolled in these courses during the data-collection period (September 2012-April 2013).

interested in student attitudes and views toward the nature of science and scientific inquiry that may have been influenced by the inquiry-based lab course in which some of the students were enrolled. This included student attitudes and views toward designing and conducting experiments-attitudes and views that, to our knowledge, are not addressed by any existing surveys. Some items from existing surveys were relevant, however.

TABLE 2. Sample of first-year biology students included in this study

\begin{tabular}{|c|c|c|c|c|}
\hline \multirow[b]{2}{*}{ Course designation } & \multirow[b]{2}{*}{ Class } & \multirow[b]{2}{*}{ Sample size $(n)$} & \multicolumn{2}{|c|}{$\begin{array}{l}\% \text { Students enrolled } \\
\text { in lab course each } \\
\text { term (term surveyed) }\end{array}$} \\
\hline & & & Term 1 & Term 2 \\
\hline \multirow[t]{2}{*}{ Standard program } & A & 164 & $\underline{29}$ & NA \\
\hline & B & 130 & 31 & $\underline{28}$ \\
\hline $\begin{array}{l}\text { Coordinated } \\
\text { first-year science } \\
\text { program }\end{array}$ & $\mathrm{C}$ & 102 & 0 & $\underline{100}$ \\
\hline $\begin{array}{l}\text { Integrated first-year } \\
\text { science program }\end{array}$ & $\mathrm{D}$ & 56 & $\underline{100}$ & NA \\
\hline
\end{tabular}

We therefore adapted items from two existing surveys: the Student Understanding of Science and Scientific Inquiry survey (SUSSI; Liang et al., 2006, 2008) and the Colorado Learning Attitudes about Science Survey (CLASS; Adams et al., 2006; adapted for biology by Semsar et al., 2011). These surveys have a closed-ended format (efficient for large-scale, in-class data collection) and demonstrated effectiveness at measuring shifts in attitudes with our targeted student demographic (Birol et al., 2014; Hansen and Birol, 2014). Following a similar methodology to that of Semsar et al. (2011) in adapting items, we examined the SUSSI and the CLASS for appropriate items relating to scientific inquiry and the nature of science, then selected five SUSSI items and two CLASS items for use in our survey. To these items we added one relevant item that had been included in the original version of the SUSSI (Liang et al., 2006). We also created six items that probed knowledge and confidence relating to scientific inquiry. All items were statements that prompted students to select one of five Likert-type responses ("strongly disagree," "disagree," "uncertain," "agree," and "strongly agree"). Where necessary, we altered the wording of pre-existing items so they referred specifically to biology and experimentation. The final survey contained 14 items, with an equal number of "agree" and "disagree" expert responses. Together, these 
TABLE 3. Categorization of attitudinal survey items based on existing literature

\begin{tabular}{|c|c|c|}
\hline Nature of science component & Attitudinal survey items & \% Expert agreement \\
\hline \multirow[t]{4}{*}{ I. Tentativeness of scientific knowledge } & Expected response: agree $(+)$ or disagree $(-)$ & \\
\hline & $\begin{array}{l}\text { 1. Biology knowledge gained through accurate experimentation will } \\
\text { NOT be changed. }{ }^{\text {a }}(-)\end{array}$ & $64^{\mathrm{b}}$ \\
\hline & $\begin{array}{l}\text { 2. Biologists can NEVER be certain that the answer to a biology research } \\
\text { question is correct. }{ }^{c}(+)\end{array}$ & $36^{\mathrm{b}}$ \\
\hline & $\begin{array}{l}\text { 3. Biologists do NOT use their imagination because it can interfere with } \\
\text { scientific reasoning. }{ }^{\text {a }}(-)\end{array}$ & 100 \\
\hline \multirow[t]{3}{*}{$\begin{array}{l}\text { II. Subjectivity, objectivity, and inferences } \\
\text { in science }\end{array}$} & $\begin{array}{l}\text { 4. If the same biology experiment is done more than once, the data that } \\
\text { are collected should always be the same. }{ }^{c}(-)\end{array}$ & $77^{\mathrm{b}}$ \\
\hline & $\begin{array}{l}\text { 5. Biologists may make different interpretations based on the same } \\
\text { observations. }{ }^{\text {a }}(+)\end{array}$ & 95 \\
\hline & $\begin{array}{l}\text { 6. Biology research is influenced by the researcher's culture and social } \\
\text { background. }(+)\end{array}$ & $73^{\mathrm{b}}$ \\
\hline \multirow[t]{2}{*}{ III. Scientific methods } & 7. The more hypotheses an experiment attempts to test, the better. ${ }^{c}(-)$ & 82 \\
\hline & 8. Biologists all follow the same step-by-step scientific method. ${ }^{\text {a }}(-)$ & $73^{\mathrm{b}}$ \\
\hline \multirow[t]{4}{*}{$\begin{array}{l}\text { IV. Relevance and accessibility of scientific } \\
\text { knowledge/inquiry }\end{array}$} & $\begin{array}{l}\text { 9. Experiments that are done under lab conditions can provide } \\
\text { information that applies to the real world. }{ }^{c}(+)\end{array}$ & 100 \\
\hline & 10. I am confident that I can design a valid biology experiment. ${ }^{c}(+)$ & 100 \\
\hline & $\begin{array}{l}\text { 11. If I had the necessary materials, I could conduct a successful biology } \\
\text { experiment. }(+)\end{array}$ & 81 \\
\hline & 12. I think about the biology I experience in everyday life. ${ }^{\mathrm{d}}(+)$ & 100 \\
\hline \multirow[t]{2}{*}{ V. Value and purpose of pure science } & $\begin{array}{l}\text { 13. The study of biology is only useful when it directly benefits human } \\
\text { health or well-being. }{ }^{\text {d }}(-)\end{array}$ & 86 \\
\hline & $\begin{array}{l}\text { 14. The primary purpose of doing a biology experiment is to establish } \\
\text { facts. }{ }^{\mathrm{e}}(-)\end{array}$ & $45^{\mathrm{b}}$ \\
\hline
\end{tabular}

aModified SUSSI item.

bItem excluded from analysis on the basis of low expert agreement.

cDeveloped by the authors for this study.

${ }^{\mathrm{d}}$ Modified CLASS item.

${ }^{\mathrm{e}}$ Modified first-draft SUSSI item.

14 items addressed five relevant nature of science components based on those identified in the literature (Table 3; Lederman et al., 2002; Liang et al., 2008). To ensure that students would interpret items in the manner intended, we first used the items (in randomized order) in three one-on-one, think-aloud interviews with first-year biology students. After the wording of five of the items was improved, the content and clarity of the final version of the attitudinal survey was evaluated by eight student interviews (Supplemental Table S1). Student interviews all followed the same protocol: subjects were randomly selected from a pool of first-year biology student volunteers; after consent was obtained, students were interviewed for up to an hour; and all interviews were audio-recorded. We also collected data regarding the accuracy and relevance of survey items by surveying 22 experts from our institution. We deliberately included in this group of experts both teaching and research faculty from a variety of biological disciplines that incorporate experimentation: cell biology, physiology, genetics, and ecology. Experts were shown the same Likert-type items used in the final student survey. If an expert responded "uncertain" to any item, he or she was asked to elaborate on this response; that is, whether it was due to a lack of certainty regarding the meaning of those statements or due to lack of a formed opinion on those topics. Expert agreement for each survey item was calculated as the percentage of experts who agreed with the expected expert-like response.

\section{Survey Administration}

Students completed the survey in class A and class D during term 1 (September - December 2012), and in class B and class C during term 2 (January - April 2013; see Table 2 for details regarding sampling design). Pretests were given during the second week of classes, and posttests were given during the last two weeks of classes. Survey items were presented to all students in the same randomized order we used for student interviews during the development of the survey. We also collected demographic data regarding students' program of study, gender, and English-language experience (years of English as the primary language at home or at school). Data collection and all other aspects of this study complied with our Behavioural Research Ethics Board-approved protocol (BREB H09-03080).

Once the student data were collected, we surveyed the instructors of classes A-D in order to identify relevant differences in instruction regarding attitudinal survey topics. Topics that were mentioned only tangentially or discussed only with students during office hours were not considered to be part of explicit instruction.

\section{Data Analysis}

Only responses from consenting first-year students who had completed both the pre- and the posttest were included in our data analysis. Participation in each course was confirmed based on the presence or absence of a final grade for that course. We 
collapsed responses along the five-point Likert scale into three categories ("expert-like," "non-expert-like," and "uncertain"), based on recommendations in the literature (Adams et al., 2006; Semsar et al., 2011). Both non-expert-like and uncertain responses were considered incorrect when calculating individual student scores (i.e., percentage of the attitudinal survey items answered in an expert-like manner). Based on feedback from experts, six of the items $(1,2,4,6,8$, and 14) contained vague and/or ambiguous statements and showed low expert agreement (i.e., <80\%). These six items were therefore excluded from the remainder of the analysis (Table 3; see Supplemental Table S2 for a list containing only those items included in the analysis).

In general, our survey score data violated the assumption of normally distributed differences (Shapiro-Wilk test) but did satisfy the assumption of homogeneity of variances (Levene's test); we therefore used two-tailed Wilcoxon signed-rank tests for matched pairs to test for significant differences in students' matched pre- and posttest attitudinal survey scores. Two-tailed Wilcoxon rank-sum tests were used to make pairwise comparisons of average test scores between groups of students, for both the pre- and posttest. Pearson's chi-squared tests were used to make comparisons among lecture classes regarding the proportion of students belonging to various demographic groups (i.e., based on English-language experience, gender, and faculty of enrollment). Bonferroni-corrected $\alpha$ values were used to determine statistical significance, based on the number of comparisons made when testing each statistical hypothesis. In all figures, error bars indicate 95\% confidence intervals; throughout the text, \pm values indicate SEM. All reported confidence intervals are based on 2000 replicates obtained via nonparametric bootstrapping.

To investigate factors associated with variation in students' posttest scores on the attitudinal survey, we treated pre- and posttest scores and lecture course and lab course final grades as continuous variables for the purposes of regression analysis. Class (i.e., A, B, C, or D) was initially included as a random variable in a linear mixed-model analysis of the data. After confirming that this random effect was not significant, we carried out the rest of our analysis using fixed-effects linear models (i.e., multiple regressions). We coded the following independent categorical variables as dummy variables: course designation (reference level = integrated first-year program vs. coordinated first-year program vs. standard program); faculty (student enrolled in faculty of science versus other faculty); English-language experience ( $\geq 10$ years of English as a primary language at home or school vs. $<10$ years); gender (female vs. male); term (term 1 vs. term 2); and lab course enrollment (reference level $=$ never enrolled vs. previously enrolled vs. currently enrolled). "Previously enrolled" indicated that the student had been enrolled in and received a final grade for the lab course in the term preceding the survey, whereas "never enrolled" indicated that the student had never been enrolled in the laboratory course. "Lab course enrollment" was later recoded as "current lab course enrollment" (currently enrolled vs. previously or never enrolled) after determining that differentiating "previously" from "never enrolled" had no significant effect. The statistical assumptions of homogeneity, independence, and normality of standardized residuals were confirmed for all linear models. All multiple regression analyses were performed with
$\mathrm{R}$, version 3.1.2 (R Core Team, 2014) using the nlme package (version 3.1-118), following a backward stepwise procedure for selecting variables; the preliminary linear mixed-model analyses testing for random effects were run using the lme4 package (version 1.1-7).

To examine relationships among the items and identify potential underlying factors in student responses to the attitudinal survey, we conducted an exploratory factor analysis of students' posttest responses using JMP, version 9.0.1 (SAS Intitute, 2010). Because we were interested in general rather than class-specific patterns, responses from all four classes $(N=$ 452) were pooled for this analysis. We used principal components to fit the factors, followed by varimax rotation. Factors were identified based on inspection of the scree plot to determine the point of inflection, as well as consideration of the interpretability of each factor. A rotated factor loading was considered to be statistically meaningful if it exceeded 0.32 (Yong and Pearce, 2013).

On the basis of the results of our factor analysis, we sorted the attitudinal survey items into groups and recalculated student pre- and posttest scores (\% expert-like responses) for each factor grouping. We then repeated our Wilcoxon signed-rank tests and linear (mixed and fixed effects-only) model analyses as outlined above, using student posttest scores for each factor grouping as dependent continuous variables. Figures were produced using either the R package ggplot2 (version 1.0.0) or Microsoft Excel, version 14.4.9 (Microsoft Corporation, 2010).

\section{RESULTS}

\section{Class Instruction}

For all four lecture classes, students received 3 hours of biology lectures per week, and all instructors intentionally illustrated concepts in their lectures using empirical data. All instructors also used clicker (personal response system)-based questions and small-group activities to promote active learning and peerto-peer discussion. However, the extent to which instructors discussed elements of the nature of science and scientific inquiry with their students varied. In general, topics that were addressed in the attitudinal survey were not explicitly included in lecture course instruction. In contrast, the lab course curriculum explicitly addressed five of the eight survey item topics (Table 4).

\section{Attitudinal Survey Results}

Overall mean posttest scores were not significantly greater than mean pretest scores, except for students in class C (Figure 1). Students in class D scored higher on the pretest than students in any of the other classes (class D: mean pretest $\%$ expert-like responses $=78.8 \pm 2.2 \%$; vs. class A: $67.20 \pm 1.4 \%, \chi^{2}=16.9, d f$ $=1, p<0.0001$; class B: $68.8 \pm 1.7 \%, \chi^{2}=9.9, d f=1, p=$ 0.0016; class C: $\left.70.3 \pm 1.6 \%, \chi^{2}=9.6, d f=1, p=0.002\right)$. Student pretest scores were not significantly different between classes A, $B$, and C ( $\alpha=0.0083)$. At the posttest level, there was no longer a significant difference between students in classes $\mathrm{C}$ and $\mathrm{D}$ (class C: mean posttest $\%$ expert-like responses $=77.2 \pm 2.0 \%$; class D: $77.9 \pm 2.6 \% ; \alpha=0.0083)$. Students in classes A and B continued to score lower than students in class D (class A: 69.4 $\pm 1.5 \%, \chi^{2}=10.3, d f=1, p=0.0014$; class B: $70.2 \pm 1.8 \%, \chi^{2}=$ 7.0, $d f=1, p=0.0083$ ) and class $C$ (class A: $\chi^{2}=10.9, d f=1, p=$ 0.001 ; class B: $\left.\chi^{2}=7.1, d f=1, p=0.0077\right)$. Expert agreement across all survey items was $92.6 \pm 2.0 \%(n=22)$. 
TABLE 4. Attitudinal survey items corresponding to topics that were explicitly addressed by first-year course curricula during the study period (ordered from highest to lowest factor loading)

\begin{tabular}{|c|c|c|c|c|c|}
\hline \multirow[b]{2}{*}{ Factor } & \multirow[b]{2}{*}{ Question } & \multicolumn{3}{|c|}{ First-Year lecture courses } & \multirow[b]{2}{*}{ First-year lab course } \\
\hline & & $\begin{array}{c}\text { Classes A and B: } \\
\text { standard program }\end{array}$ & $\begin{array}{c}\text { Class C: Coordinated } \\
\text { first-year science } \\
\text { program }\end{array}$ & $\begin{array}{c}\text { Class D: Integrated } \\
\text { first-year science } \\
\text { program } \\
\end{array}$ & \\
\hline Factor 1: & 11 & No & No & No & Yes \\
\hline \multirow[t]{2}{*}{ Confidence and interest } & 10 & No & Yes & No & Yes \\
\hline & 12 & No & Yes & No & No \\
\hline \multirow[t]{4}{*}{ Understanding and acceptance } & 5 & No & No & No & Yes \\
\hline & 3 & No & No & No & Yes \\
\hline & 9 & No & No & No & Yes \\
\hline & 7 & No & No & No & No \\
\hline \multirow[t]{2}{*}{ Items with $<80 \%$ expert agreement } & 1 & No & No & No & Yes \\
\hline & 14 & No & No & No & Yes \\
\hline
\end{tabular}

See Table 3 for details regarding questions and Table 6 for details regarding factors loadings.

Our multiple regression analysis suggests that several factors influenced students' attitudinal survey responses at the end of term (Table 5). The strongest predictor of a student's posttest score was his/her pretest score. Other positive predictors of posttest score included current enrollment in the lab course and 10 or more years of English-language experience. The interaction terms for these variables were not significant. All other factors being equal, being currently enrolled in the lab course and having 10 or more years of English-language experience each increased students' posttest scores by $\sim 5-7 \%$ (Table 5 and Figure 2). Enrollment in the Faculty of Science, course designation, term, and gender effects on posttest scores were all nonsignificant in light of the other effects.

Our exploratory factor analysis suggested that the eight items could be grouped into two factors on the basis of stu-

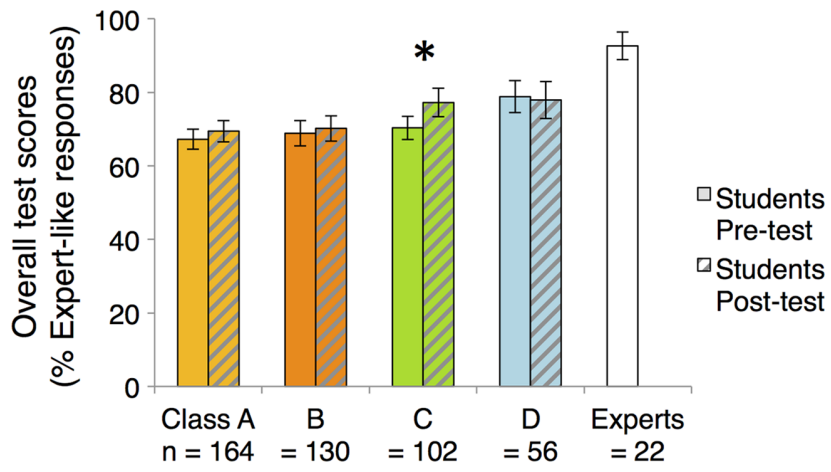

FIGURE 1. Comparison of overall pre- and posttest\% expert-like responses on the survey. Students' paired pre- and posttest scores were significantly different in class $C\left(^{*}, p=0.0012 ; \alpha=0.0125\right)$. Error bars $=95 \%$ confidence intervals for the mean. dents' posttest responses. Inspection of the scree plot showed that eigenvalues began leveling off after the second component (Supplemental Figure S1). Only the first two factors had eigenvalues of $\geq 1$. Furthermore, extracting two factors resulted in two distinct clusters of items, with no cross-loadings (i.e., all items had a loading of 0.32 or higher for one factor and only one factor; see Table 6 for details). Together, these factors account for $38.6 \%$ of the total shared variance in student responses; this magnitude of explained variance is comparable to that in other factor analyses of surveys regarding student attitudes toward science and research (Papanastasiou, 2005;

TABLE 5. Results from a multiple regression analysis of first-year student attitudes toward scientific inquiry

\begin{tabular}{ll}
\hline Independent variables & \multicolumn{1}{c}{$\begin{array}{c}\text { Dependent variable }=\text { overall } \\
\text { posttest score } \\
\text { (\% expert-like responses) }\end{array}$} \\
\hline Intercept $\quad \boldsymbol{\beta}[$ [95\% CI]; $\boldsymbol{\beta}$
\end{tabular}

${ }^{a} \beta=$ unstandardized regression coefficients; $\beta=$ standardized regression coefficients; $\mathrm{CI}=$ confidence interval. Variables were excluded from the model if they did not have a significant effect; an effect is considered significant if its 95\% CI does not include zero.

${ }^{\mathrm{b}}$ Excluded 32 students due to missing responses regarding English-language experience. 


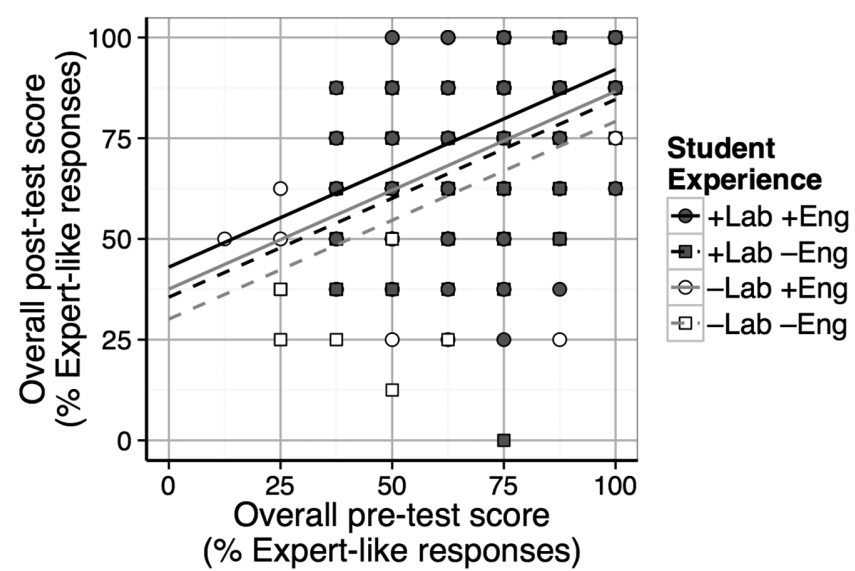

FIGURE 2. Relationship between student attitudes and views regarding scientific inquiry and other variables, as inferred via multiple regression analysis. Fitted lines show predicted posttest\% expert-like responses based on pretest\% expert-like responses and students' English-language experience and lab course enrollment $(n=420)$. At the time of survey participation, students were: + Lab, currently enrolled in the lab course (dark gray points, black lines), or-Lab, previously or never enrolled in the lab course (white points, light gray lines); and +Eng, $\geq 10$ years English-language experience (circles, solid lines), or -Eng, $<10$ years English-language experience (squares, dashed lines). See Table 5 for full statistical results.

Hilpert et al., 2008; Brookstein et al., 2011; Fujiwara et al., 2012). After carefully examining items in each factor grouping, we proposed general descriptions for each of the factors: factor 1: confidence and interest in scientific inquiry; factor 2 : understanding and acceptance of scientific inquiry.

Factor 1: Confidence and Interest in Scientific Inquiry Three of the four items that had been assigned a priori to the same nature of science component (relevance and accessibility of scientific knowledge/inquiry; Table 3) fell into the first

TABLE 6. Factor analysis results, based on student posttest responses across all classes

\begin{tabular}{lccc}
\hline Nature of science component $^{\mathrm{a}}$ & Item & Factor $\mathbf{1}$ & Factor $\mathbf{2}$ \\
\hline \multicolumn{4}{l}{ Factor 1: Confidence and interest in scientific inquiry (three items) } \\
IV & 11 & 0.787 & -0.041 \\
IV & 10 & 0.775 & 0.016 \\
IV & 12 & 0.509 & 0.179 \\
Factor 2: Understanding and acceptance of scientific inquiry \\
$\quad$ (five items) \\
V & 13 & -0.061 & 0.596 \\
II & 5 & -0.0364 & 0.570 \\
II & 3 & 0.166 & 0.547 \\
IV & 9 & 0.039 & 0.521 \\
III & 7 & 0.190 & 0.500 \\
Percentage of variance & \multicolumn{4}{l}{} \\
Cumulative percentage & \multicolumn{4}{l}{19.36} & 19.19 \\
\hline
\end{tabular}

${ }^{\text {a }}$ See Table 3 for details regarding items and nature of science components.

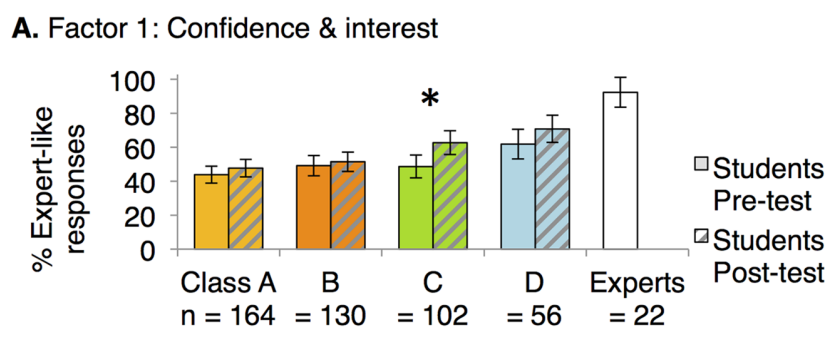

B. Factor 2: Understanding \& acceptance

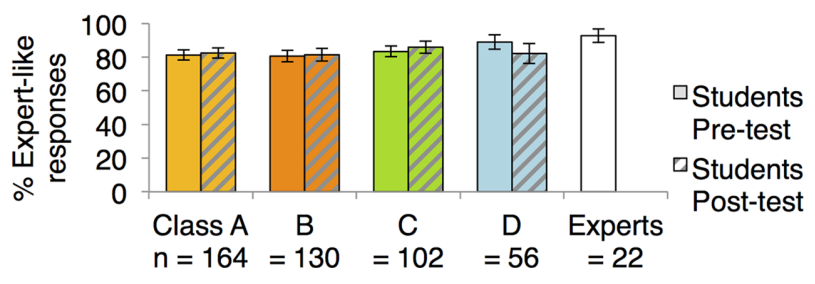

FIGURE 3. Comparison of pre- and posttest\% expert-like responses for different aspects of student attitudes toward scientific inquiry. (A) Students in class $C$ showed significant differences in paired pre- and posttest scores for factor 1 items $\left({ }^{*} p=0.0004\right.$; $\alpha=0.0125$ ). (B) In the case of factor 2 items, there were no significant differences between students' paired pre- and posttest scores $(\alpha=0.0125)$. Error bars $=95 \%$ confidence intervals for the mean.

grouping. Two of these items directly assessed student confidence in designing and conducting biology experiments; the third assessed personal interest in biology outside course work. For these items, class $\mathrm{C}$ was the only class in which students scored significantly higher in the posttest than in the pretest (Figure 3A). Class D students had relatively high factor 1 pretest $\%$ expert-like responses compared with other classes; however, this difference was only significant for class A (class D: $61.9 \pm 4.4 \%$; class A: $43.9 \pm 2.5 \%, \chi^{2}=12.4, d f=1, p=0.0004$; class B: $49.2 \pm 3.0 \%$; class C: $48.7 \pm 3.4 \%$; $\alpha=0.0083)$. There were no significant differences in factor 1 pretest scores between students who were enrolled in the lab course and those who were not for either class A or B. On the posttest, both classes A and $\mathrm{B}$ had a significantly lower percentage of expert-like responses than class D (class D: $70.8 \pm 4.5 \%$; vs. class A: $47.8 \pm$ $2.6 \%, \chi^{2}=19.0, d f=1, p<0.0001$; vs. class B: $51.5 \pm 3.0 \%, \chi^{2}$ $=13.9, d f=1, p=0.0002 ; \alpha=0.0083$ ). class A posttest $\%$ expertlike responses were also significantly lower than those of class $\mathrm{C}$ (class C: $62.7 \pm 3.5 \% ; \chi^{2}=11.5, d f=1, p=0.0007$ ). There were no significant differences between classes A and B, or class $\mathrm{C}$ and $\mathrm{D}$, in either pre- or posttest scores on factor 1 items. In general, student scores were lower for factor 1 items than for factor 2 (understanding and acceptance of scientific inquiry). Lecture course final grades were not significantly associated with students' posttest scores; instead, current enrollment in the lab course was a strong positive predictor (14.09\% increase in expert-like responses), followed by English-language experience (8.14\% increase in expert-like responses; see Table 7 and Figure $4 \mathrm{~A})$. No other variables were significant predictors of factor 1 posttest scores. Expert agreement was $92.4 \pm 3.0 \%$ for these items $(n=22)$. 
TABLE 7. Results from multiple regression analysis of first-year student attitudes toward two different aspects of scientific inquiry

\begin{tabular}{|c|c|c|}
\hline \multirow[b]{2}{*}{ Independent variables } & \multicolumn{2}{|c|}{ Dependent variable $=$ posttest scores (\% expert-like responses) } \\
\hline & $\begin{array}{l}\text { Factor 1: Confidence and interest } \\
\qquad \beta[95 \% \mathrm{CI}] ; \beta\end{array}$ & $\begin{array}{l}\text { Factor 2: Understanding and acceptance } \\
\qquad \beta[95 \% \mathrm{CI}] ; \beta\end{array}$ \\
\hline Intercept & $18.33[12.13,24.60]$ & $29.14[15.82,42.59]$ \\
\hline Currently enrolled in lab course & $14.09[8.83,19.48] ; 0.20$ & - \\
\hline Lecture course final grade & - & $0.25[0.08,0.42] ; 0.14$ \\
\hline$\geq 10$ years English experience & $8.14[2.03,14.32] ; 0.10$ & $7.22[2.37,12.12] ; 0.16$ \\
\hline Pretest score & $0.49[0.41,0.57] ; 0.48$ & $0.36[0.24,0.47] ; 0.32$ \\
\hline Multiple $R^{2}$ & $31.7 \%$ & $20.5 \%$ \\
\hline Adjusted $R^{2}$ & $31.2 \%$ & $19.9 \%$ \\
\hline$F(\mathrm{df} 1, \mathrm{df} 2)$ & $64.38(3,416)$ & $35.67(3,416)$ \\
\hline$p$ & $<2.2 \times 10^{-16}$ & $<2.2 \times 10^{-16}$ \\
\hline$n$ & $420^{\mathrm{a}}$ & $420^{\mathrm{a}}$ \\
\hline
\end{tabular}

${ }^{2}$ Excluded 32 students due to missing responses regarding English-language experience. $\beta=$ unstandardized regression coefficients; $\beta=$ standardized regression coefficients. Variables were excluded (-) if they did not have a significant effect; an effect is considered significant if its 95\% CI does not include zero.

\section{Factor 2: Understanding and Acceptance} of Scientific Inquiry

The majority of attitudinal survey items (five out of eight) fell into the second factor grouping. There were no significant differences between students' pre- and posttest scores for these items in any of the four classes (Figure 3B). Pretest\% expert-like responses in class $\mathrm{C}(83.3 \pm 1.6 \%)$ were not significantly different from those in class D $(88.9 \pm 2.0 \% ; \alpha=0.0083)$. Although class D scored higher on factor 2 items in the pretest than classes A and B (class A: $81.2 \pm 1.5 \%, \chi^{2}=7.1, d f=1, p=$ 0.0077 ; class B: $\left.80.6 \pm 1.7 \%, \chi^{2}=8.4, d f=1, p=0.0038\right)$, posttest $\%$ expert-like responses were not significantly different between any of the classes (class A: $82.4 \pm 1.6 \%$; class B: 81.4 $\pm 1.9 \%$; class C: $85.9 \pm 1.9 \%$; class D: $82.1 \pm 3.0 \% ; \alpha=0.0083$ ). Compared with the items in the first factor grouping (confidence and interest in scientific inquiry), students scored rela- tively high on factor 2 items. In addition to pretest scores, students' lecture course final grades and English experience were both positive predictors of factor 2 posttest scores; no other variables had significant effects (Table 7 and Figure 4B). Expert agreement was $92.7 \pm 2.1 \%$ for these items $(n=22)$.

\section{Student Demographics and Academic Performance}

There were no significant differences among lecture classes in English-language experience $\left(\chi^{2}=6.7, d f=3, N=420\right.$, $p=0.083)$; on average, $26.2 \%$ students reported fewer than 10 years of English experience. The four classes also had equivalent proportions of male versus female students $\left(61.0 \%\right.$ female; $\chi^{2}=$ $5.8, d f=3, N=438, p=0.12$ ). As expected, classes A and B had fewer Faculty of Science students (74.4 and 56.2\%, respectively) than classes C and D (100\%). Lecture course final grades were higher in class $\mathrm{D}(78.1 \pm 1.7 \%)$ than in any of the other

\section{A. Factor 1: Confidence \& interest}

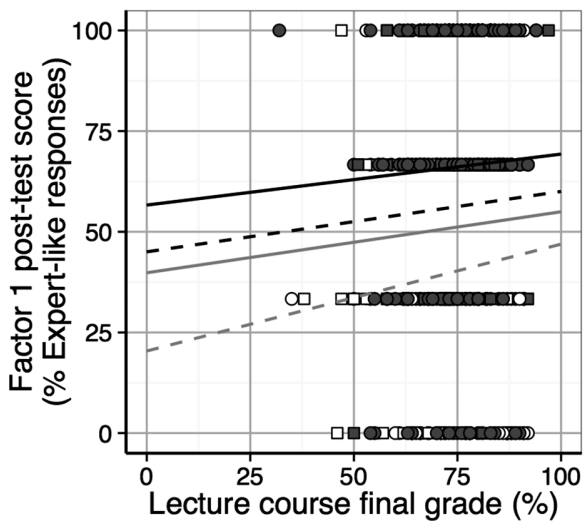

\section{B. Factor 2: Understanding \& acceptance}

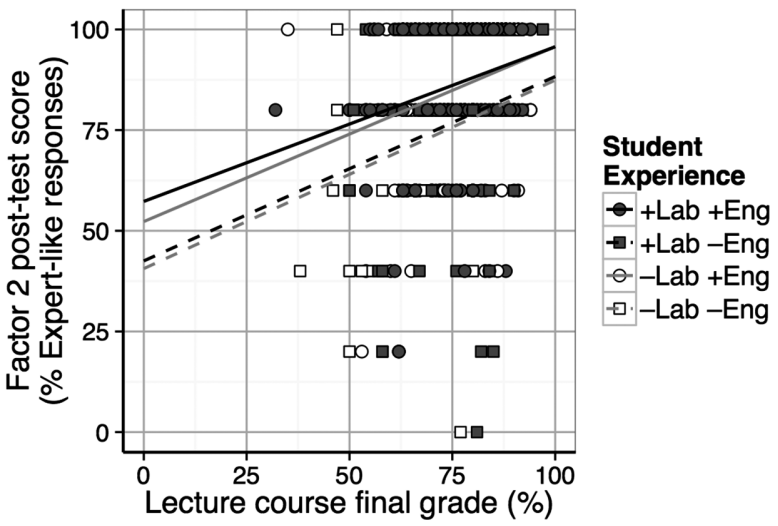

FIGURE 4. Relationship between students' attitudes and views regarding different aspects of scientific inquiry and other variables, as inferred via multiple regression analysis. Fitted lines show predicted posttest\% expert-like responses for (A) factor 1 survey items and (B) factor 2 survey items as based on lab course enrollment, lecture course final grades, English-language experience, and pretest\% expert-like responses. At the time of survey participation, students were: +Lab, currently enrolled in the lab course (dark gray points, black lines), or-Lab, previously or never enrolled in the lab course (white points, light gray lines); and +Eng, $\geq 10$ years English-language experience (circles, solid lines), or -Eng, < 10 years English-language experience (squares, dashed lines). (A) Lab course enrollment, but not lecture course final grades, has a significant effect on factor 1 posttest scores; (B) lecture course final grades, but not lab course enrollment, have a significant effect on factor 1 posttest scores. See Table 7 for detailed statistical results. 
classes, although this difference was only significant for classes $\mathrm{B}$ and C (class A: $74.8 \pm 0.9 \%$; class B: $73.2 \pm 0.9 \%, \chi^{2}=10.6$, $d f=1, p=0.0011$; class C: $73.2 \pm 0.8 \%, \chi^{2}=13.4, d f=1, p=$ $0.0002 ; \alpha=0.0083$ ).

\section{DISCUSSION}

Our investigation shows that it is possible for first-year students to acquire greater confidence and interest in the nature of science and the process of scientific inquiry over the course of one term. Students in our study who were enrolled in an inquiry-based lab course became significantly more expert-like in their attitudes and views toward scientific inquiry and in their confidence and self-efficacy as scientists. Although such shifts have been reported in comparisons of first-year and fourth-year biology students (Semsar et al., 2011; Hansen and Birol, 2014), it is unusual to see significant shifts toward more expert-like attitudes and views in the first year of studies (Brewe et al., 2009; Semsar et al., 2011; Ding and Mollohan, 2015) or consistently across diverse aspects of scientific inquiry (Desaulniers Miller et al., 2010; Birol et al., 2014).

We observed significant shifts toward more expert-like attitudes and views in one of the four classes we surveyed (Figure 1 ). The students in this class (class C) started with relatively non-expert-like attitudes regarding the nature of science, as did students in classes A and B. However, by the end of the term, class $\mathrm{C}$ students had made small but significant transitions toward more expert-like responses, comparable to those observed in class D. Class D students expressed relatively more expert-like attitudes and views than students in the other classes preinstruction, but showed no significant differences in attitudes and views postinstruction (Figure 1). Others have also found that certain groups of students (e.g., science majors, high-performing students) express more expert-like attitudes preinstruction, followed by a subsequent deterioration or lack of significant improvement in attitudes postinstruction (Hansen and Birol, 2014; Ding and Mollohan, 2015). Students in class D were expected to be high performing and science oriented for several reasons: these students were all science majors, had higher average high school grade point averages (GPAs) than students in other classes, and were required to take part in a specialized application process that likely precludes enrollment by students with low interest or aptitude in the sciences (Table 1; Dryden et al., 2012).

Our general observation that students begin their first-year of university with relatively novice-like attitudes and views regarding science is consistent with findings reported elsewhere for students in biology (Desaulniers Miller et al., 2010; Semsar et al., 2011; Birol et al., 2014; Hansen and Birol, 2014; Ding and Mollohan, 2015) and other science disciplines (Perkins et al., 2005; Adams et al., 2006; Barbera et al., 2008; Otero and Gray, 2008; Brewe et al., 2009). It is not uncommon for students to demonstrate a regression in expert-like attitudes and views or a decrease in self-confidence in the first year of their studies (Butler et al., 2008); in contrast, some of the students in our study appear to have improved or maintained their attitudes and views regarding science and scientific inquiry. Despite this, mean overall student survey scores at the end of term were still significantly below those of experts (Figure 1). This suggests that many students continued to hold relatively novice-like attitudes and views even at the end of the term, possibly due to particularly persistent non-expert-like attitudes and views or resistance to questioning and revising their beliefs (Perry, 1970; Magolda, 1992).

Looking across classes, our results indicate that current enrollment in the lab course may be an important predictor of student attitudes and views toward science (Figure 2 and Table 5). Using exploratory factor analysis, we extracted two important axes of variation in students' posttest responses: confidence and interest in scientific inquiry; and understanding and acceptance of scientific inquiry. By considering each of these elements individually, we were able to gain additional insight into the various factors related to changes in student attitudes and views.

\section{Factor 1: Confidence and Interest in Scientific Inquiry}

Factor 1 was characterized by three items that fell into the predetermined nature of science component: relevance and accessibility of scientific knowledge/inquiry (Tables 2 and 6). These items directly addressed students' ability to relate biological knowledge to their everyday experiences, and their confidence in designing and conducting experiments. Three of the classes did not shift significantly with regard to these items; classes A and B maintained a relatively low level of expert-like attitudes and views toward confidence and interest in scientific inquiry $(<52 \%)$, whereas class D exhibited a nonsignificant shift from 61.9 to $70.8 \%$ between the beginning and end of the term. In contrast, class C made significant gains in terms of expert-like responses to factor 1 items, from 48.7 to $62.7 \%$ (Figure 3A). These gains may be due in part to the fact that all of the students in class $\mathrm{C}$ were enrolled in the lab course during the term in which they were surveyed (Table 2); the results of our multiple regression analysis indicate that current enrollment in the lab course did have a positive effect on students' factor 1 posttest scores (Table 7). In addition, these students were also the only ones to receive explicit, lecture course instruction in two of the three topics related to factor 1 items (Table 4). Explicit instruction regarding the scientific process may have increased student familiarity and interest; the experience of an inquiry-based lab course would have provided these students with practice doing science.

Across classes, we found that students' personal interest and confidence in scientific inquiry at the end of the term were independent of their academic success. All students, regardless of their academic ability, were equally receptive to gains in interest and confidence, whereas posttest scores for items relating to understanding and acceptance of scientific inquiry (factor 2) appeared to be limited by students' academic ability (Table 7). This is in contrast with other reports of students' perceived level of competence being correlated with their performance in undergraduate biology courses (Partin and Haney, 2012). Our findings suggest that experiential learning in the form of inquiry-based laboratories can contribute to increasing individuals' confidence and/or self-efficacy in scientific investigation and can potentially increase students' interest in science. Providing students with experience in scientific inquiry can increase their perception that they are able to do research (Handelsman et al., 2004; Adedokun et al., 2013; Robnett et al., 2015). Students who are confident in their abilities to complete a task are more likely to persist until it is completed, whereas individuals with low self-confidence often give up 
quickly when faced with difficulty (Bandura, 1986). If inquiry-based learning is able to increase confidence and interest even for low-performing students, it may also increase their motivation and time on task, thereby increasing their potential for learning gains in the long run. It is important to note, however, that students who had been enrolled in the lab course the previous term did not appear to have greater confidence or interest than students who had never taken the lab course, all other factors considered. A single course in the first year may therefore be insufficient in terms of improving student confidence and interest over the long term.

\section{Factor 2: Understanding and Acceptance of Scientific Inquiry}

Five of the final eight survey items fell into a cluster we identified broadly as understanding and acceptance of scientific inquiry (Table 6). These items address the value, relevance, and subjectivity of scientific inquiry and knowledge (Table 3). Students scored relatively high on factor 2 items at the start of the term (mean pretest $\%$ expert-like responses were $\geq 82 \%$ for all four classes; Figure 3B). Our results are generally consistent with those of related studies; Desaulniers Miller et al. (2010) found that students in both introductory and upper-level courses had relatively high pretest scores for the SUSSI items that are related to our factor 2 items. Although Birol et al. (2014) found no overall change in student responses to SUSSI items between the beginning and end of an introductory science seminar course, they also observed a relatively high proportion of expert-like attitudes in related items.

None of the classes in our study showed significant shifts toward more expert-like responses in the posttest for factor 2 items (Figure 3B). This may be partly due to the fact that, in almost all cases, topics relating to these questions were not explicitly discussed in any of the lecture classes (Table 4). Students who took the first-year lab course would have been exposed to many of these topics, but we found no evidence that enrollment in the lab course was related to student scores on questions related to understanding and acceptance of scientific inquiry (Table 7). We did find evidence, however, that high-performing students (based on lecture course final grades) exhibited marginal but significantly higher posttest scores on these items than low-performing students across classes. This suggests that students in our sample population who are interested in science and/or who are academically motivated will acquire expert-like attitudes regarding factor 2 items, regardless of the biology classes in which they are enrolled. It also suggests that low-performing students may continue to exhibit relatively non-expert-like understanding and acceptance of scientific inquiry, despite enrollment in inquiry-based courses.

\section{Shifts in Student Attitudes and Views as a Result of Explicit Instruction in Scientific Inquiry}

Our data clearly indicate that students who are enrolled in an inquiry-based lab course develop more expert-like attitudes toward biology as a science, especially in terms of their interest and confidence. This effect manifested itself across all four classes in our study, even when other sources of variation were accounted for (Tables 5 and 7). In the inquiry-based course, students are guided through carefully designed activities that help them think and act like scientists. This type of explicit instruction and engagement in the scientific process reinforces the nature of science concepts and facilitates shifts in student attitudes. Other researchers have found that, unless course curricula explicitly target attitudes and beliefs regarding science and scientific inquiry, student attitudes become less expert-like over the short term (Perkins et al., 2005; Adams et al., 2006; Barbera et al., 2008; Semsar et al., 2011; Birol et al., 2014; Ding and Mollohan, 2015). In contrast to these studies, biology courses with curricula designed to enhance development of student attitudes toward science have reported no regression or small gains in expert-like attitudes (Nomme and Birol, 2014). This link between course curricula and student attitudes has also been documented in physics (Perkins et al., 2005). In a revised physics class in which students were required to practice science through building, validating, and deploying models, Brewe et al. (2009) found that student attitudes toward physics became more expert-like. There is accumulating evidence that inquiry-based activities that emphasize the nature of scientific knowledge and the scientific method are important curricular elements to avoid regression and enhance the transition of student attitudes toward science.

\section{Influence of English Experience and Attitudes toward Science}

One of the concerns we had in the development and employment of the attitudinal survey was the high proportion of international students at our university. Approximately $25 \%$ of our sample population reported fewer than 10 years of English-language experience. We took great care during the survey development process to ensure that the attitudinal survey statements could be sufficiently understood by students, despite variation in English-language experience and abilities. Despite this, whether a student had more or fewer than 10 years of English experience was a significant predictor of his or her posttest score. Our results suggest that students in our study population with fewer than 10 years of English as a primary language should be expected to score $7.5-8 \%$ lower on the posttest, in terms of expert-like responses, than other students (Tables 5 and 7); this effect appears to be independent of other factors, including lab course enrollment. However, the effect of lab course enrollment on survey posttest scores was likewise independent of English-language experience. If participating in the inquiry-based lab course has some positive impact on confidence and interest in science, our results suggest that a lack of English-language experience does not impede that benefit. Possible relationships between English-language experience and understanding/confidence in scientific inquiry are worthy of further investigation.

\section{Limitations}

We acknowledge that there are several limitations to the conclusions we can make on the basis of our study. There is the potential for recruitment of biased samples in observational studies such as this one (Brownell et al., 2013), due to the fact that students self-select by way of enrolling in or applying for particular classes. Students' motives for choosing particular classes may be influenced by their career goals and may be associated with certain attitudes and views toward science. At this institution, all students continuing in life sciences programs are required to enroll in the inquiry lab course. Whether 
students enroll in the inquiry lab course in the first or second term is usually determined by the schedule of other courses. We are confident, however, that our high rate of survey participation, large sample size, and analysis of pretest scores has helped to minimize concerns regarding sample bias. A second limiting factor is the method we used to characterize instruction regarding certain topics in the lecture and lab classes. Explicit classroom instruction in nature of science topics was inferred on the basis on qualitative, self-reported data (course materials and interviews with instructors); implementation of an appropriate classroom observations protocol would capture quantitative data on the occurrence of explicit instruction on these topics. Finally, we recognize that this study was conducted at a large research university and that the students are, by virtue of the high admission standards, those who have been relatively academically successful in high school. The results from our study may therefore not be directly applicable to some other postsecondary institutions; a wider survey of students in different institutions could address this concern. Despite these limitations, we are confident that our data effectively characterizes firstyear biology students studying at this university.

\section{CONCLUSIONS}

First-year students begin their undergraduate studies holding a diversity of attitudes and views toward science, spanning the continuum from novice to expert. If one of the goals of a science undergraduate education is to engage first-year students in constructing scientific knowledge and shifting them toward expertlike attitudes and views, then providing students with inquiry-based experiences is a means to that end. Explicit and targeted instruction in the nature of science can be introduced to lecture courses, but our data suggest that experiential learning in the context of an inquiry-based lab may be required for students to gain confidence. Our findings indicate that enrollment in an inquiry-based lab course appears to benefit all students in terms of facilitating the development of more expert-like attitudes and views toward science. This is true even for students with fewer incoming expert-like attitudes and views or potential language barriers. However, our findings suggest that a onetime intervention in the first year may not be enough to shift students away from persistent non-expert-like attitudes and views. Concepts regarding the nature of science may need to be explicitly reinforced during subsequent years of study to achieve longterm shifts in these areas. Overall, our results support the hypothesis that the inclusion of explicit instruction related to the nature of science can positively influence student attitudes and views toward scientific inquiry - a finding that can be directly applied to the improvement of university science curricula.

\section{ACKNOWLEDGMENTS}

Thank you to all the students who participated in this study and, specifically, to the instructors, James Cooke, Brett Couch, and Pam Kalas, for allowing us to collect data in their classes and for providing information regarding their teaching practices. Also, thank you to the experts who donated their time to provide us with essential expert responses regarding our survey. Finally, thank you to the anonymous reviewers who provided constructive suggestions that greatly improved our manuscript. This research was financially supported through institutional funding for education research in the sciences (Teaching and Learning Enhancement Fund of the University of British Columbia and Science Centre for Learning and Teaching Development Fund).

\section{REFERENCES}

Abd-El-Khalick F, Lederman NG (2000). The influence of history of science courses on students' views of nature of science. J Res Sci Teach 37, 1057-1095.

Adams WK, Perkins KK, Podolefsky NS, Dubson M, Finkelstein ND, Wieman CE (2006). New instrument for measuring student beliefs about physics and learning physics: the Colorado Learning Attitudes about Science Survey. Phys Rev Spec Top Phys Educ Res 2, 1-14.

Adedokun OA, Bessenbacher AB, Parker LC, Kirkham LL, Burgess WD (2013) Research skills and STEM undergraduate research students' aspirations for research careers: mediating effects of research self-efficacy. J Res Sci Teach 50, 940-951.

Allen D, Tanner K (2005). Approaches to biology teaching and learning: from a scholarly approach to teaching to the scholarship of teaching. Cell Biol Educ 4, 1-6

Allen D, Tanner KD (2009). Transformations: Approaches to College Science Teaching, New York: Freeman.

Ambrose SA, Bridges MW, DiPietro M, Lovett MC, Norman MK (2010). How Learning Works: Seven Research-Based Principles for Smart Teaching, San Francisco: Jossey-Bass.

American Association for the Advancement of Science (2011). Vision and Change in Undergraduate Biology Education: A Call to Action, Washington, DC.

Bandura A (1986). The explanatory and predictive scope of self-efficacy theory. J Soc Clin Psychol 4, 359-373.

Barbera J, Adams WK, Wieman CE, Perkins KK (2008). Modifying and validating the Colorado Learning Attitudes about Science Survey for use in chemistry. Chem Educ Res 85, 1435-1439.

Beck C, Butler A, Burke da Silva K (2014). Promoting inquiry-based teaching in laboratory courses: are we meeting the grade? CBE Life Sci Educ 13, 444-452.

Birol G, Deane T, Cassidy A, Fox JA (2014). Impact of a first year seminar in science on undergraduate students' views on the nature of science. Int $J$ Sci Math Tech Learn 20, 65-83

Brewe E, Kramer L, O'Brien G (2009). Modeling instruction: positive attitudinal shifts in introductory physics measured with CLASS. Phys Rev Spec Top Phys Educ Res 5, 013102.

Briggs ARJ, Clark J, Hall I (2012). Building bridges: understanding student transition to university. Qual Higher Educ 18, 3-21.

Brookstein A, Hegedus S, Dalton S, Moniz R, Tapper J (2011). Measuring Student Attitude in Mathematics Classrooms, Dartmouth: Kaput Center for Research and Innovation in STEM Education, University of Massachusetts.

Brownell SE, Klose MJ, Fukami T, Shavelson RJ (2013). Context matters: volunteer bias, small sample size, and the value of comparison groups in the assessment of research-based undergraduate introductory biology lab courses. J Microbiol Biol Educ 14, 176-182.

Butler DL, Pollock C, Nomme KM, Nakonechny J (2008). Promoting authentic inquiry in the sciences: challenges faced in redefining university students' scientific epistemology. In: Inquiry In Education: Overcoming Barriers to Successful Implementation, ed. BM Shore, MW Aulls, and MAB Delcourt, New York: Taylor \& Francis, 301-324.

Campisi J, Finn KE (2011). Does active learning improve students' knowledge of and attitudes toward research methods? J Coll Sci Teach 40, $38-45$

Chen S, Chang W-H, Lieu S-C, Kao H-L, Huang M-T, Lin S-F (2013). Development of an empirically based questionnaire to investigate young students' ideas about nature of science. J Res Sci Teach 50, 408-430.

Deslauriers L, Schelew E, Wieman CE (2011). Improved learning in a large-enrollment physics class. Science 332, 862-864.

Desaulniers Miller MC, Montplaisir LM, Offerdahl EG, Cheng F-CC, Ketterling $\mathrm{GL}$ (2010). Comparison of views of the nature of science between natural science and nonscience majors. CBE Life Sci Educ 9, 45-54. 
Ding L, Mollohan KN (2015). How college-level introductory instruction can impact student epistemological beliefs. J Coll Sci Teach 44, 19-27.

Dryden N, Leander C, Louis-Martinez D, Nakahara H, MacLean M, Waltham C (2012). Are we doing any good? A value-added analysis of UBC's science one program. Can J Schol Teach Learn 3, ar4.

Eastwell P (2010). The scientific method: critical yet misunderstood. Sci Educ Rev 9, 8-12.

Edmondson KM, Novak JD (1993). The interplay of scientific epistemological views, learning strategies, and attitudes of college students. J Res Sci Teach 30, 547-559.

Fujiwara T, Laulathaphol P, Phillips BJ (2012). Thai university students' scientific epistemic beliefs: relationships with past learning experiences. Procedia Soc Behav Sci 69, 187-196.

Gire E, Jones B, Price E (2009). Characterizing the epistemological development of physics majors. Phys Rev Spec Top Phys Educ Res 5, 6.

Hanauer DI, Dolan EL (2014). The Project Ownership Survey: measuring differences in scientific inquiry experiences. CBE Life Sci Educ 13, 149-158.

Handelsman J, Ebert-May D, Beichner R, Bruns P, Chang A, DeHaan R, Gentile J, Lauffer S, Steward J, Tilghman SM, et al. (2004). Scientific teaching Science 304, 521-522.

Hansen MJ, Birol G (2014). Longitudinal study of student attitudes in a biology program. CBE Life Sci Educ 13, 331-337.

Hiebert SM (2007). Teaching simple experimental design to undergraduates: do your students understand the basics? Adv Physiol Educ 31, 82-92.

Hilpert J, Stump G, Husman J, Kim W (2008). An Exploratory Factor Analysis of the Pittsburgh Freshman Engineering Attitudes Survey, 38th ASEE/IEEE Frontiers in Education Conference, Saratoga Springs, NY: IEEE, 9-14.

Hofer BK (2004). Epistemological understanding as a metacognitive process: thinking aloud during online searching. Educ Psychol 39, 43-55.

Hoskins SG, Lopatto D, Steven LM (2011). The C.R.E.A.T.E. approach to primary literature shifts undergraduates' self-assessed ability to read and analyze journal articles, attitudes about science, and epistemological beliefs. CBE Life Sci Educ 10, 368-378.

Lederman NG, Abd-El-Khalick F, Bell RL, Schwartz RS (2002). Views of nature of science questionnaire: toward valid and meaningful assessment of learners' conceptions of nature of science. J Res Sci Teach 39, 497-521.

Lederman NG, Wade PD, Bell RL (1998). Assessing the nature of science: what is the nature of our assessments? Sci Educ 7, 595-615.

Liang LL, Chen S, Chen X, Kaya ON, Adams AD, Macklin M, Ebenezer J (2006). Student Understanding of Science and Scientific Inquiry (SUSSI): Revision and Further Validation of an Assessment Instrument. 2006 Annual Conference of the National Association for Research in Science Teaching (NARST), 5-8 April 2006, San Francisco, CA.

Liang LL, Chen S, Chen X, Kaya ON, Adams AD, Macklin M, Ebenezer J (2008). Assessing preservice elementary teachers' views on the nature of scientific knowledge: a dual-response instrument. Asia-Pac Forum Sci Learn Teach 9, 1.

Magolda MBB (1992). Students' epistemologies and academic experiences: implications for pedagogy. Rev High Ed 15, 265-87.
Microsoft Corporation (2010). Microsoft Excel, Redmond, WA.

National Research Council (1996). National Science Education Standards, Washington, DC: National Academies Press.

Nomme K, Birol G (2014). Course redesign: an evidence-based approach. Canadian J Sch Teaching and Learning 5, 1-28.

Osborne J, Simon S, Collins S (2003). Attitudes towards science: a review of the literature and its implications. Int J Sci Educ 25, 1049-1079.

Otero VK, Gray KE (2008). Attitudinal gains across multiple universities using the Physics and Everyday Thinking curriculum. Phys Rev Spec Top Phys Educ Res 4, 020104.

Papanastasiou EC (2005). Factor structure of the "Attitudes Toward Research" scale. Int Assoc Stat Educ 4, 16-26.

Partin ML, Haney JJ (2012). The CLEM model: path analysis of the mediating effects of attitudes and motivational beliefs on the relationship between perceived learning environment and course performance in an undergraduate non-major biology course. Learn Environ Res 15, 103-123.

Partin ML, Haney JJ, Worch EA, Underwood EM, Nurnberger-Haag JA Scheuermann A, Midden WR (2011). Yes I can: the contributions of motivation and attitudes on course performance among biology nonmajors. J Coll Sci Teach 40, 86-95.

Perkins KK, Adams WK, Pollock SJ, Finkelstein ND, Wieman CE (2005). Correlating student beliefs with student learning using the Colorado Learning Attitudes about Science Survey. In: 2004 Physics Education Research Conference, ed. J Marx, P Heron, and S Franklin, New York: American Institute of Physics, 61-64.

Perry WG (1970). Forms of Intellectual and Ethical Development in the College Years: A Scheme, New York: Holt.

Perry WG (1981). Cognitive and ethical growth: the making of meaning. In: The Modern American College, ed. AWCa Associates, San Francisco: Jossey-Bass, 76-116.

Prince $M$ (2004). Does active learning work? A review of the research. J Eng Educ 93, 223-231.

R Core Team (2014). R: A Language and Environment for Statistical Computing, Vienna, Austria: R Foundation for Statistical Computing.

Robnett RD, Chemers MM, Zurbriggen EL (2015). Longitudinal associations among undergraduates' research experience, self-efficacy, and identity. J Res Sci Teach 52, 847-867.

SAS Institute (2010). JMP: Statistical Discovery, Cary, NC: Statistical Analysis System.

Semsar K, Knight JK, Birol G, Smith MK (2011). The Colorado Learning Attitudes about Science Survey (CLASS) for use in biology. CBE Life Sci Educ 10, 268-278.

Smith KA, Sheppard SD, Johnson DW, Johnson RT (2005). Pedagogies of engagement: classroom-based practices. J Eng Educ 94, 87-101.

Tsai CC, Liu SY (2005). Developing a multi-dimensional instrument for assessing students' epistemological views toward science. Int J Sci Educ 27, 1621-1638.

Yong AG, Pearce S (2013). A beginner's guide to factor analysis: focusing on exploratory factor analysis. Tutor Quant Methods Psychol 9, 79-94. 